\title{
Oxidative Stress and Birth Defects in Infants of Women with Pregestational Diabetes
}

\author{
Sonia Clapés PhD, Tammy Fernández MD, Gipsis Suárez MD
}

\begin{abstract}
Hyperglycemia characteristic of diabetes mellitus triggers pathological processes in fetal development of various structures such as the retina, peripheral nerves, renal glomerulus, and arterial and venous beds. Women with diabetes prior to conception have children with birth defects three to five times more frequently than women without diabetes. There is no specific pattern of birth defects, but the central nervous and cardiovascular systems are the most affected. Hyperglycemia leads to mitochrondrial superoxide radical production, which activates five metabolic pathways that mediate damage leading to diabetic embryopathy. Once oxidative stress is established, there is modification of gene expression controlling embryonic development in critical periods. Vitamin E application in animal models has greatly lowered occurrence of birth defects in embryonic and fetal stages, consistent with an etiologic role for oxidative stress in dysmorphogenesis. Effective metabolic control before and during pregnancy, achieved in Cuba by implementing programs for control of birth defects in children of diabetic pregnant women, has been found effective.
\end{abstract}

KEYWORDS Diabetes mellitus, hyperglycemia, oxidative stress, gene expression, glucose metabolism disorders, congenital abnormalities, birth defects, Cuba

\section{INTRODUCTION}

Diabetes mellitus (DM) is a complex disease that requires lifelong treatment and causes potentially fatal complications.[1] It is characterized by elevated blood glucose (fasting blood glucose $>126 \mathrm{mg} / \mathrm{dL}$ or $7.0 \mathrm{mM}$ ),[2] caused by total or partial loss of insulin action, the hormone that stimulates glucose entry into tissues.[3] Both type 1 (formerly insulin-dependent or juvenile diabetes) and type 2 (adult-onset or noninsulin-dependent) DM show genetic predisposition due to multiple polymorphisms that interact with different triggering agents, such as viral infections in the case of type $1 \mathrm{DM}$ and obesity in the case of type 2.[2,3]

From $5 \%$ to $9 \%$ of diabetics have type 1 DM,[1-3] while type 2 DM accounts for approximately $90 \%$ of all cases with a definitive diagnosis.[2] Estimated global prevalence of undiagnosed DM or glucose intolerance is $5 \% .[3,4]$ Globally, DM is considered one of the most frequent causes of avoidable mortality, with six diabetics dying every minute.[1-3] According to Cuba's Ministry of Public Health (MINSAP. the Spanish acronym), in 2011, 309,702 women were living with DM in Cuba, 43,840 of them (14.2\%) of reproductive age. The same year, DM was the seventh leading cause of death in women and was responsible for 4.1 years of potential life lost per thousand women with diabetes.[5]

\section{HYPERGLYCEMIA IS THE CAUSE OF MORBIDITY}

\section{IN DIABETES}

Sustained hyperglycemia leads to development of pathological processes affecting the retina, peripheral nerves, kidney glomerulus, and the arterial and venous beds.[2] It is also a risk factor for development of atherosclerotic lesions, which reduce blood flow to the brain, lower limbs and heart.[2] With such a plethora of organs and systems affected, it is among the most costly diseases worldwide, for both families and health systems.[1]

But one DM complication is infrequently mentioned in the literature: birth defects in infants of diabetic mothers, the only DM complication that differentially affects the sexes (paternal DM does not induce birth defects, since the maternal environment is the determining factor).[6-8] The explanation for hyperglycemia's teratogenic effects was reported 31 years ago, when Freinkel[6] postulated that metabolic pathway precursor substances, such as glucose, mediated this association, coining the term diabetic embryopathy for abnormalities developing between the sixth and eighth weeks of embryonic development.[7,8]

Birth defects in infants of diabetic mothers Reducing birth defects in infants of diabetic mothers is a challenge for modern medicine. First, birth defects occur during the embryonic stage - the first eight weeks of gestation-when most women are still unaware they are pregnant. Second, there is evidence that even moderate and transient hyperglycemic episodes trigger the sequence of events leading to birth defects.[9,10] Third, treatment with insulin or its modern analogues improves chances of maternal and fetal survival but does not in itself reduce birth defects.[1,2,4] Fourth, although there have been encouraging results from strict glycemic control before and during pregnancy,[4] birth defects are still more common in infants of women with pregestational DM than in those of nondiabetic pregnant women.[6-9]

From $6 \%$ to $13 \%$ of children of women with pregestational DM have some degree of dysmorphogenesis or abnormal tissue formation.[9] Gestational DM develops after the $20^{\text {th }}$ week, when embryogenesis is complete, and so does not induce diabetic embryopathy.[10-12] While there have been some reports of birth defects in infants of women with gestational DM, it is likely that these mothers in fact had type 2 DM preconception, perhaps undiagnosed because of discrete changes in blood glucose levels.[12,13] Given increased DM incidence globally and the trend to earlier age of type $2 \mathrm{DM}$ onset, it is reasonable to fear an impending increase in incidence of birth defects from this cause. $[1,2,13]$

Birth defects affecting children of mothers with pregestational DM involve most organs, but particularly the central nervous and cardiovascular systems (CNS and CVS, respectively). These types of developmental abnormalities occur because of a deficit in neural crest cell migration and survival, related to neural tube closure and formation of cardiac and craniofacial structures.[7]

Cardiovascular birth defects-including tricuspid and mitral valve atresia, transposition of the large vessels and arteries, truncus arteriosus, and venous and arterial outlet defects-are 
the most common in the general population, and two to five times more frequent in infants of diabetic mothers than in those of nondiabetic mothers.[6-9] A large group of CNS malformations such as anencephaly, spina bifida and microcephaly are among those suffered by children of diabetic mothers, $[8,9,12,13]$ mainly derived from incorrect neural tube closure. It has been shown that, at least in the CVS and CNS, the main defects are promoted by an increase in apoptotic pathways.[8] The PAX3 gene controls p53 protein, stimulating its degradation by binding it to several ubiquitin molecules. When PAX3 gene expression is reduced, p53 protein is unregulated and apoptosis increases (Figure 1).[7,13]

Figure 1: Mechanism by which hyperglycemia leads to dysmorphogenesis

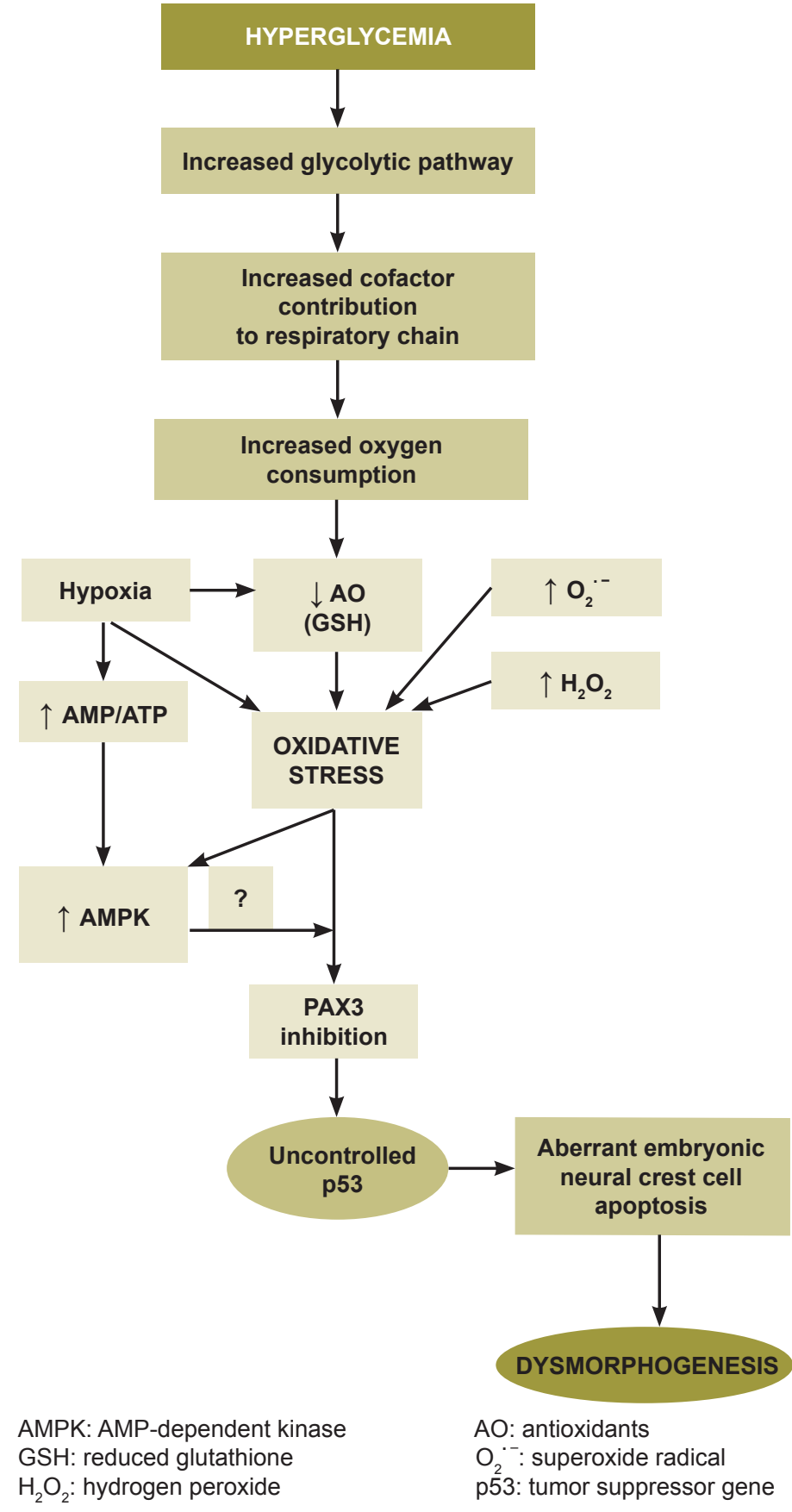

The common mechanism causing diabetic complications: mitochondrial superoxide radical production The production of reactive oxygen species (ROS) is crucial in DM pathogenesis and complications.[2] Hyperglycemia activates multiple metabolic pathways that produce these reactive species. Mitochondrial superoxide radical production is the central path in which five main pathways converge, activated under hyperglycemic conditions: 1) nonenzymatic protein glycosylation that produces advanced glycosylation end products (AGE); 2) acceleration of the polyol pathway (controlled by the enzyme aldose reductase) with consequent decrease in $\mathrm{NADPH}$, the cofactor of the antioxidant enzyme glutathione reductase and other intermediate products; 3 ) increased hexosamine pathway activity, in which $\mathrm{N}$-acethyl glucosamine is formed; 4 ) increased expression of the AGE receptor and its ligands; and 5) activation of protein kinase $\mathrm{C}$ isoforms.[3]

The molecular basis of birth defect development is directly related to the metabolic changes that activate these pathways. Modification of several enzymes controlling these pathways and changes in the cellular redox state trigger multiple cell signals involving dozens of mediator molecules.[3,8,13] In recent years more detailed evidence has emerged concerning these hyperglycemia-activated pathways that constitute the molecular basis of birth defects, discussed below.

Molecular basis of birth defects in infants of diabetic mothers Oxidative stress (OS) certainly affects embryonic development, although not by a direct genotoxic effect, as previously thought.[13] OS has been shown to affect adequate expression of some genes characteristic of the various stages of embryonic development. Each gene affected has specific sensitivity to hyperglycemic conditions and changes in the cellular redox state; the whole process depends on molecular signals that are still being explored.[7,13]

The idea that OS mediates occurrence of birth defects led Loeken to theorize about the deleterious effect of the combination of hyperglycemia and oxidative stress: in very early stages of their development, embryonic structures express glucose transporters and, because the placenta is not yet formed, develop normally under hypoxic conditions (8-12\% oxygen compared to $20 \%$ in maternal circulation).[8,13] This is exacerbated when embryonic structures are exposed to hyperglycemia.

The manner in which OS orchestrates participation of different molecules with diverse functions and locations within the cell includes, besides establishing hypoxia in the embryo, an increase in superoxide radical production, decreased bioavailability of antioxidants, and consequent OS, which, as previously mentioned, results in reduced PAX3 gene expression. $[8,13]$

It was not until 2011 that the way in which OS reduces PAX3 gene expression became known. It involves AMPK, an enzyme with kinase activity that is activated in response to an increase in adenosine monophosphate nucleoside (AMP) levels.[8,13] An increased AMP/ATP ratio occurs in hypoxic conditions with low nutrient and energy availability.[13,14] AMPK participates in regulation of energy metabolism and once activated moves into the cell nucleus and phosphorylates multiple proteins, among them hypoxia-inducible factor $1 \alpha$. The question now arises of how all these covalent modifications in the nucleus caused by AMPK, lead to events resulting in CNS and CVS defects (Figure 1). What is beyond doubt is that modification of AMPK is caused by ROS and leads directly to birth defects.[13] 
In summary, the events underlying birth defect development include: hyperglycemia, hypoxia, increased ROS production, AMPK activation, decreased PAX3 gene expression and, therefore, loss of control of p53 protein, and aberrant neural crest cell apoptosis. All this leads to abnormalities in structures derived from neural crest cells which in turn lead to infant birth defects.[12,13]

Experimental studies in Cuba The relationship between OS and birth defects in infants of diabetic mothers is being studied by our research group.[15] We found that application of vitamin $E$ as an antioxidant in pregnant diabetic rats resulted in a decrease in fetal deaths and resorptions. OS markers in diabetic rats treated with vitamin $E$ were not modified, but the morphological study of renal tissue showed evident signs of recovery in comparison to untreated rats.[15] Other groups have shown reduction of birth defects and changes in levels of biomolecule oxidation in the mothers, [9] while the expression of genes related to proteins involved in antioxidant defense was modified favorably.[9,13] Although all these were rodent trials and must be replicated in higher mammals, Vitamin $E$ holds promise for birth defect prevention in humans.

\section{BIRTH DEFECTS IN CUBA}

In Cuba, birth defects are the second cause of death in children aged $<1$ year and the first in those aged 1 to 4 years.[5] Nevertheless, birth defects occurred in only $1.1 \%$ (129) of all live births in $2011,[5]$ a statistic comparable to those of highly socioeconomically developed countries and the result of a MINSAP program providing free genetic counseling to all pregnant women.[16]

Cuba's National Comprehensive Diabetes Pregnancy Program[17] is included in MINSAP's National Maternal-Child Care Program (PAMI, the Spanish acronym).[18] Its main purpose is to provide specialized care to pregnant women with DM, with reduction of birth defects and perinatal deaths one of its most important objectives. The Program includes 23 provincial DM and pregnancy services and extends to primary health care in all municipalities, providing DM reproductive risk clinics for women with pregestational DM (upon physician or self referral). Program data indicate that 2536 children were born to mothers with pregestational DM from 2003 through 2011. One indicator of program impact is that birth defects decreased over the same period without an explanatory increase in therapeutic abortions.[17]

Despite ensured access to demonstrably effective preconception care, a relatively low percentage of diabetic women in reproductive age $(50.8 \%)$ take advantage of these specialized services. [17] Nevertheless, program success is evident in cumulative statistics through 2011: birth defects occurred in only $0.5 \%$ of children born to diabetic mothers who maintained good metabolic control, and the perinatal death rate was $0.4 \%$. This is in dra- matic contrast to $6.7 \%$ birth defects and $6.1 \%$ perinatal deaths in children born to women without good metabolic control before and during pregnancy.[17] All this is consistent with the results of the Diabetes Control and Complications Trial, over more than 11 years, showing that intensive treatment of type $1 \mathrm{DM}$ can delay onset of complications and death.[19] It also demonstrated that intensive treatment of women with pregestational DM can reduce birth defects, a conclusion supported by other studies.[4,19]

Prospects for reducing birth defects In September 2011, the International Diabetes Federation reported 336 million people living with type 2 DM globally.[1] In the United States 4.6 million people die of DM every year; diabetics represent $12 \%$ of its population, and spending on their daily health care is $\$ 612$ million. [1] In Cuba, with a health system that implements innovative and humanistic policies, diabetic care nevertheless also represents a constant challenge and generates substantial costs.

The challenge involves scientific institutions, which should focus on the advances in understanding birth defects' molecular causes. Commitments are needed, and not just by the state, which must, of course, ensure specialized care and the resources needed to achieve goals set forth by experts (regarding blood glucose monitors, medications, etc.) Couples-and diabetic women of reproductive age especially - also have an obligation to efficiently use resources and facilities provided free of cost or publicly subsidized by the national health system.

In 2012, the US Food and Drug Administration approved a new class of drug for DM control: selective insulin receptor modulators. [20] Although it is too early to draw definitive conclusions about long-term success of this novel therapy, it may promise insulin's beneficial effects without the adverse ones, providing hope for healthy pregnancy outcomes for millions of diabetic women worldwide_-if costs are not prohibitive.

\section{CONCLUSIONS}

We now understand more about the causes of birth defects in infants of diabetic women and about the possibility of their control through medication. Since oxidative stress has been identified as having a role in birth defect pathogenesis, the most suitable drug candidate would be a preparation with antioxidant action. The time is not far off for considering routine antioxidant therapy for pregnant women with pregestational DM. In Cuba, this is feasible due to provision for all diabetics by the national health system of the necessary resources for adequate metabolic control. Intervention programs in Cuba and elsewhere have proven that DM-induced birth defects are as avoidable as DM deaths. However, even more important than political policies and programs per se are education, current information, and responsible use of services among those affected. $-1 /$ -

\section{REFERENCES}

1. Ashcroft FM, Rorsman P. Diabetes mellitus and the $\beta$ Cell: the last ten years. Cell. 2012 Mar $16 ; 148(6): 1160-71$.

2. Inzucchi SE. Clinical practice. Diagnosis of diabetes. N Engl J Med. 2012 Aug 9;367(6):542-50.

3. Giacco F, Brownlee M. Oxidative stress and diabetic complications. Circ Res. 2010 Oct 29;107(9):1058-70.

4. Diabetes Control and Complications Trial Research Group. Pregnancy outcomes in the
Diabetes Control and Complications Trial. Am J Obstet Gynecol. 1996 Apr;174(4):1343-53.

5. Anuario Estadístico 2011 [Internet]. Havana: Ministry of Public Health (CU); 2012 [cited 2012 Jun 23]. Available from: http://files.sld.cu/dne/ files/2012/04/anuario-2011-e.pdf. Spanish.

6. Freinkel N. Banting Lecture 1980. Of pregnancy and progeny. Diabetes. 1980 Dec;29(12):1023-35.

7. Fetita LS, Sobngwi E, Serradas P, Calvo F, Gautier JF. Consequences of fetal exposure to mater- nal diabetes in offspring. J Clin Endocrinol Metab. 2006 Oct;91(10):3718-24.

8. Loeken MR. Advances in understanding the molecular causes of diabetes-induced birth defects. Soc Gynecol Investig. 2006 Jan;13(1):2-10.

9. Ericksson UJ, Cederberg J, Wentzel P. Congenital malformations in offspring of diabetic mothers. Animal and human studies. Rev Endocr Metab Disord. 2003 Mar;4(1):79-93. 
10. González E. Diabetes experimental: etiología de malformaciones congénitas en descendientes de ratas diabéticas. Rev Cubana Endocrinol. 2002;13(1):53-63. Spanish

11. Farrell T, Neale L, Cundy T. Congenital anomalies in the offspring of women with type 1, type 2 and gestational diabetes. Diabet Med. 2002 Apr;19(4):322-6.

12. Chen CP. Congenital malformations associated with maternal diabetes. Taiwanese J Obstet Gynecol. 2005 Mar 1:44(1):1-7.

13. Wu Y, Viana M, Thirumangalathu S, Loeken MR AMP-activated protein kinase mediates effects of oxidative stress on embryo gene expression in a mouse model of diabetic embryopathy. Diabetologia. 2012 Jan;55(1):245-54.

14. Long $Y C$, Zierath JR. AMP-activated protein kinase signaling in metabolic regulation. $\mathrm{J}$ Clin Invest. 2006 Jul;116(7):1776-83.

15. Gorrita Y, Núñez N, Fernández T, Clapés S. Malformaciones congénitas en la descendencia de ratas diabéticas [Congenital anomalies in diabetic rats descendants]. Rev Haban Cienc Med. Spanish. Forthcoming.
16. Marcheco B. El programa nacional de diagnóstico, manejo y prevención de enfermedades genéticas y defectos congénitos de Cuba: 19812009. Rev Cubana Genética Comun. 2009;3 (2-3):167-84. Spanish.

17. Guillén M, Valdés L, Lang J. Programa Nacional Cubano de Atención Integral a la Gestante con Diabetes Mellitus. Conferencia. Libro resumen COPAEN 2012. XIII Congreso Latinoamericano de Endocrinología; 2012 May 11; Havana, Cuba. p 11. Spanish.

18. Álvarez AG, García A, Gorbea MH. Pautas conceptuales y metodológicas para explicar los determinantes de los niveles de salud en Cuba. Rev Cubana Salud Pública. 2007;33(2). Spanish.

19. McElvy SS, Miodovnik M, Rosenn B, Khoury JC, Siddigi T, Dignan PS, et al. A focused preconceptional and early pregnancy program in women with type 1 diabetes reduces perinatal mortality and malformation rates to general population levels. J Matern Fetal Med. 2000 Jan-Feb;9(1):14-20.

20. Vigneri R, Squatrito $S$, Frittitta L. Selective insulin receptor modulators (SIRM): a new class of antidiabetes drugs? Diabetes. 2012 May;61(5):984-5.

\section{THE AUTHORS}

Sonia Clapés Hernández (Corresponding author: sclapes@infomed.sld.cu), chemica engineer with a doctorate in health sciences. Full professor, biochemistry department, Vic toria de Girón Basic and Preclinical Science Institute (ICBP), Medical University of Havana, Cuba.

Tammy Fernández Romero, clinical biochemist. Associate professor, biochemistry department, ICBP, Medical University of Havana, Cuba.

Gipsis Suárez Román, clinical biochemist. Assistant professor, biochemistry department, ICBP, Medical University of Havana, Cuba.

Submitted: July 3, 2012

Approved for publication: January 8, 2013

Disclosures: None 